\title{
Comer, Matar e Outras Desavenças Culinárias
}

\author{
Eating, Killing And Other Culinary Disagreements
}

\author{
Laísa Fernandes Tossin \\ Diversitas - Núcleo de Estudos das Diversidades, Intolerâncias e Conflitos \\ Biblioteca Brasiliana Guita e José Mindlin (BBM) \\ Universidade de São Paulo (USP)
}

Resumo. Neste artigo, traço as relações que compõem o tecido ideológico que sustenta o processo de significação e de estabelecimento dos sentidos profundamente opacos presentes nas materialidades linguísticas: yakú (comer papa ou goma) e yani (comer carne de caça ou peixe) em Macuxi; e hau (comer papa) e hebu (comer peixe ou carne de caça) em Kulina. Exponho a estratégia de produção permanente de comida, a mobilidade causada pelas necessidades sazonais (chuva e seca), oscilando entre a vida na aldeia, nos períodos de estiagem e a vida nos tesos, em pequenos grupos, no período da cheia, para discutir a existência de "um real" independente de discursos feitos a seu respeito. No encontro entre duas discursividades distintas, portanto entre "dois reais" distintos, a universalidade representada pela homogeneidade lógica é posta em questão, rompendo com as relações epistemologicamente construídas entre estrutura de processos mentais e designação, permeada pela possível construção de "um real" não comum e não universal.

Palavras-chave: Semântica da Enunciação; Designação em Kulina e Macuxi; Verbo "comer"; Formações Discursivas em Kulina e Macuxi; Memória Discursiva Regionalizada.

\begin{abstract}
In this article, I trace the relationships that make up the ideological fabric that supports the process of signification and the establishment of deeply opaque meanings present in linguistic materials: yakú (eating porridge or gum) and yani (eating game or fish) in Macuxi; and hau (eating porridge) and hebu (eating fish or game meat) in Kulina. I explain the strategy of permanent food production, the mobility caused by seasonal needs (rain and drought), oscillating between life in the village, in the dry periods and life in the treasures, in small groups, during the flood season, to discuss existence of "a real" independent of speeches made about it. In the encounter between two distinct discursivities, therefore between different "two reals", the universality represented by logical homogeneity is called into question, breaking with the epistemologically constructed relationships between the structure of mental processes and designation, permeated by the possible construction of "not a real". common and not universal.
\end{abstract}

Keywords: Discourse semantics; Designation in Kulina and Macuxi languages; Verb "to eat"; Discursive formation in Kulina and Macuxi languages; Regionalized discoursive memory.

\section{Artes culinárias: as artes do bem-viver ${ }^{1}$}

Neste artigo, assumo a posição de que a semântica é uma disciplina linguística que tem o objetivo de compreender o funcionamento das línguas. Sendo esse funcionamento parte fundamental do modo de significar o mundo, de falar sobre o mundo e de fazer referência ao mundo. A semântica entende

1. Agradeço aos amigos Gilton Mendes dos Santos e Miguel Aparício por suas cuidadosas leituras e grandes contribuições ao entendimento das relações produtivas aqui apresentadas. Agradeço também à parecerista anônima que muito contribuiu com a qualidade da análise presente neste artigo. 
que a palavra não é o mundo, mas é uma forma de o sujeito se relacionar com o real. Relacionar-se com o social e o natural, ou seja, o real, são formas de constituição do sujeito traçadas na história, nas disputas e relações de poder onde os processos discursivos se dão. O processo de assujeitamento é o processo de constituição dos sentidos, tanto nas formulações analíticas da Análise do Discurso quanto nas da Semântica, sendo este o ponto onde ambas as disciplinas se encontram.

Estas perspectivas se preocupam com a construção discursiva dos referentes e com os processos de significação. A esse processo de construção, Pêcheux (2009, p. 160) chamou de formação discursiva. A formação discursiva é aquilo que, em uma dada conjuntura sócio-histórica, determina o que pode ser dito. Esta determinação do que pode ser dito ou não vem do fato de que as formações discursivas representam, no discurso, as formações ideológicas que produzem as evidências do sentido (ORLANDI, 1999, p. 46). A mediação entre o humano e a realidade social e natural produz um trabalho simbólico que está na base da existência humana. Essa condição simbólica da produção do discurso é a presença da ideologia controlando os limites da interpretação dos sentidos expressos na materialidade da língua. Assim, a ideologia se materializa no discurso e o discurso se materializa na língua, promovendo uma relação circular de alimentação que remete a espaços abertos sempre suscetíveis de estruturações e reestruturações que não são dados a priori, mas que se constituem como a permanência das transformações mútuas entre humano e realidade.

Ao dizer que as transformações mútuas permanecem na materialidade da língua, tratamos inevitavelmente da memória na produção do discurso. É justamente a memória que aciona o contexto sócio-histórico presente no saber discursivo que torna possível todo o dizer e que retorna sob a forma do já-dito. É, portanto, fundamental para entender o funcionamento do discurso e a sua relação com a ideologia e o sujeito, pois dá forma à memória constitutiva do discurso, em outro termo, do interdiscurso. A realidade, deste modo, passa por um processo ideológico de construção, que tem uma história, guardada em uma memória discursiva, materializada na língua por meio do discurso. Assim, os sentidos não se esgotam em si porque não são conteúdos associados ao real, mas são sentidos historicamente construídos no discurso pela ideologia gerada na constituição dos sujeitos em suas relações com o real e o natural, possibilitando a relação entre coisa e palavra.

Nesta relação entre coisa e palavra, os sentidos não são dados a priori, mas têm sua história de constituição recontada à medida que a análise identifica as filiações sócio-históricas presentes no discurso que a formulou. As diferenças entre formações discursivas distintas são fruto do processo histórico em que as posições dos sujeitos são constituídas. Por isso, derivam de diferenças ideológicas e mudam de sentido. A partir da premissa elaborada por Brèal em seu Ensaio de Semântica de 1897 de que os sentidos das palavras mudam, entendo que o sentido não está associado à morfologia, mas, de acordo com Pechêux (2009, p. 165) está associado às dinâmicas ideológicas que sustentam as bases discursivas do sentido. Pechêux se vale da definição althusseriana de ideologia para descrever o funcionamento ideológico do discurso, que versa sobre a ideia, de modo amplo e bem abrangente, de que a ideologia é tudo o que dá coesão às dinâmicas sociais cotidianas, proposta à qual Pechêux adicionou a premissa de que os discursos fazem significar a realidade gerada pelas dinâmicas sociais.

São estas as relações que compõem o tecido ideológico que sustenta o processo de significação e de estabelecimento dos sentidos nesta análise. As dinâmicas históricas de manejo, assentamento e mobilidade são entendidos como gestos de interpretação sobre a realidade efetuados pelo sujeito que fala e que deixaram suas marcas na materialidade da língua. Expõem, portanto, a estratégia de 
produção permanente de comida, a mobilidade causada pelas necessidades sazonais (chuva e seca), oscilando entre a vida na aldeia, nos períodos de estiagem, e a vida nos tesos, em grupos menores, no período da cheia.

A partilha deste modo de vida, desta maneira de fazer comida, de criar sentidos, destas artes de fazer e de combinar práticas e usos, é que estabelece, ao mesmo tempo que produz, uma rede de relações sociais e simbólicas (CERTEAU, 2003, p. 42). Segundo Certeau (2003, p. 47), para se estudar as práticas orais das línguas deve-se restituir às práticas cotidianas sua legitimidade como construtoras de lógicas. Práticas como caminhar, caçar, falar, cozinhar, habitar, apresentam táticas de desempenho e de uso, combinadas a partir de elementos heterogêneos tais como: a ocasião, a sorte, a oportunidade e a astúcia que remontam a imemoriais inteligências e apresentam continuidades e permanências. Estas táticas quando partilhadas nos servem como indicações de uma regionalização de determinadas memórias discursivas, explicitando uma rede de relações sócio-históricas e políticas que se articulam em um jogo ideológico de apropriações linguísticas e ressignificações da vida dentro e entre grupos que vivem conectados a esta rede, seja ela geograficamente próxima ou não.

Considerar o poder de circulação desta rede de relações sócio-históricas e políticas para a formação e estabelecimento de uma rede de sentidos ideologicamente compartilhados, significa entender os processos anteriores à chegada dos europeus a este continente, como processos históricos e políticos, e não como meros processos de migração populacional e empréstimos lexicais por transferência de tecnologia.

\section{Um parênteses para a circulação de sentidos}

Para ilustrar as considerações expostas no item anterior, vou trazer o caso dos Apinajé que estudei no mestrado. Os Apinajé são um dos grupos Jê que habitam o Brasil Central. Suas aldeias circulares com caminhos radiais e uma praça central foram tradicionalmente construídas ao longo do rio Tocantins, mas não à beira d'água, e ocupam o território hoje conhecido como Bico do Papagaio. Como relatado por Nimuendajú (1956, p. 1-2), as primeiras referências aos Apinajé apareceram nos textos do jesuíta Antonio Vieira que, entre 1633 e 1658, realizou quatro entradas ao Sertão com o fim de fazer descimentos de índios para o aldeamento de Belém. Ele esteve na região, medida por latitude e minuto, como era costume da época, que correspondia exatamente ao atual território Apinajé, mas os índios resgatados nesse território foram Tupinambás e Potiguares, como descrito pelo jesuíta. O entendimento geral, a partir daí, é que povos Tupi habitavam a região que, após ser despovoada pelos missionários em seus resgates e descimentos, foi ocupada pelos Apinajé. Da perspectiva dos Apinajé, eles sempre estiveram no território deles. Em 1721, outro jesuíta o padre Manoel Motta encontrou, na mesma região, um povo "tão estranho e verdadeiramente novo, que tinham por asco ver homens vestidos". Descreveuos como sendo os Óto, auto-nomeação cujo significado é "pontal", o canto de terra onde dois rios confluem. Somente em 1774, quando os Óto cercaram, atacaram e impediram a passagem de Antonio Luiz Tavares, os Apinajé começaram a fazer parte da documentação colonial, por meio dos relatos de seus conflitos com colonos e a administração da colônia. Nesses relatos, há descrição das incursões para captura de escravos, as correrias feitas pelos índios para levar ferramentas e armas dos postos da administração e as matanças. 
Que os Apinajé só foram nomeados como Apinajé, no período colonial, em decorrência dos conflitos já não é novidade alguma. A surpresa que encontrei nesse relatório de Nimuendajú foi a menção aos primeiros índios capturados no território dos Apinajé que não eram Apinajé, mas Tupinambás e Potiguares. Tomar a impressão do padre Antonio Vieira para considerar que aquele era um território Tupi antes de ser Apinajé parece uma explicação às cegas. A única prova que ampara esta ideia é a existência de pequenas peças de cerâmica decorada encontrada pelos próprios Apinajé em um local próximo à aldeia Bacaba, como nos informou Nimuendajú (1956, p. 13). Mesmo assim, não há evidências de que se trata de cerâmica de outro grupo étnico. Estas peças poderiam ser restos de uma produção de cerâmica anterior que foi abandonada como atividade do grupo ou fruto de troca com outros grupos, ambas as atividades desenvolvidas muito tempo antes da chegada de Nimuendajú entre eles. A simples associação da presença de peças de cerâmica com a consideração do padre Antonio Vieira de que os índios capturados eram Tupinambás e Potiguares não esclarece a existência de um território Tupi anterior naquele local. De fato, podemos nos interpelar de modo mais profundo se os índios capturados pelo jesuíta, sendo Tupinambá e Potiguar, não eram apenas Apinajé. O que faria dos Apinajé semelhantes aos Tupinambá e aos Potiguar?

Costuma-se entender as populações Jê como parcialmente isoladas dos demais grupos, supostamente eles viviam à margem das trocas comerciais que circulavam pelo continente ou participavam perifericamente de um "escambo silencioso [com os tupi-guarani], envolvendo as famosas pedras verdes (para a confecção de tembetás) e penas (para a confecção de adornos)." ${ }^{2}$ Na carta de Caminha, já havia uma referência a tais pedras. "Trazia este velho o beiço tão furado, que lhe caberia pelo furo um grande dedo polegar, e metida nele uma pedra verde, ruim, que cerrava por fora esse buraco."3 Ângelo Corrêa (2011, p. 232) relatou suas recentes descobertas arqueológicas a respeito de uma indústria lítica voltada para a produção de tembetás para trocas em um sítio localizado ao sul do Ceará. A presença da pedra no local e a existência de inúmeros tembetás produzidos sem alcançarem a etapa final de lapidação devido às imperfeições da pedra que geravam rachaduras ou rupturas demonstram que havia uma atividade concentrada naquela região de produção de tembetás que atendiam às necessidades de outros assentamentos ou grupos étnicos. Segundo C. F. Ott (1944, p. 22), não há dúvida a respeito do uso de tembetás entre os Tupinambá e os Tupiniquim. Mas é bem provável que os tembetás feitos de pedra tivessem sido mais usados no sertão, onde havia abundância do material empregado em seu fabrico, principalmente da pedra verde e, como geralmente se admite, os habitantes do litoral recebiam do sertão os exemplares necessários. Alfred Métraux (1979, p. 168) supôs "que os tupinambá aprenderam com os tapuias o uso do botoque." Os Jês ou Tapuias não eram periféricos nem estavam à margem da importante rede de trocas e circulação de sentidos que se articulava por uma grande extensão territorial, pois usar botoque ou tembetá possui um significado comum a quem o usa, mas a designação de um tembetá nos mais diferentes grupos que o usam não carrega consigo necessariamente morfologia. Assim entendido, podemos perceber que há um preconceito que torna os grupos do Brasil Central mais selvagens que os do litoral. Ser mais selvagem implicaria produzir uma cultura material inferior em qualidade técnica e estética que os outros grupos e, por isso mesmo, tomar emprestados técnica e léxico. Pois as suposições mais correntes consideram que a transferência de tecnologia implica empréstimo lexical.

2. Os índios antes do Brasil, de Carlos Fausto, 2010, p. 80.

3. A carta de Pero Vaz de Caminha. O descobrimento do Brasil, de Silvio Castro, 2015, p. 61. 
O próprio Nimuendajú nos dá algumas informações que cruzam os limites étnicos estabelecidos para cada grupo, sugerindo algum tipo de relacionamento entre os grupos que não se limitavam às guerras. Um ritual bastante Tupinambá praticado pelos Apinajé e descrito por Nimuendajú (1956, p. 68) é o choro cerimonial, também chamado de saudação lacrimosa, desprendido pelas mulheres quando algum parente ou visitante querido retornava à aldeia. Este choro é acompanhado de lamentações é realizado por todas as mulheres aparentadas da pessoa que chegou. Nimuendajú descreveu esse evento quando ele mesmo havia retornado à aldeia depois de um longo período sem fazer uma visita. A descrição desse choro cerimonial ou da saudação lacrimosa apareceu em Anchieta e Jean de Léry como uma das coisas marcantes e impressionantes sobre os Tupi da Guanabara, em geral, junto com o ritual antropofágico. Alfred Métraux (1979, p. 157-161) descreveu a saudação lacrimosa como um rito de polidez entre os Tupinambá e fez um levantamento da literatura divulgada até o momento de produção de seu livro A religião dos Tupinambás para compilar as informações sobre a ocorrência da saudação lacrimosa em diferentes grupos indígenas. Dessas informações elaborou um mapa que mostra a dispersão do rito pelo litoral Atlântico e o centro-oeste, chegando, ao norte, até Cayena, e alcançando a América Central, apresentando dispersão por toda a região do Mississipi até a costa do Texas, na América do Norte. Os autores citados por Alfred Métraux elaboraram conjecturas a respeito das origens do rito e das razões que levam as mulheres a chorarem os recém-chegados, mas nenhum deles se debruçou sobre o fato de que o rito extrapola os limites linguísticos, étnicos e territoriais dos grupos estudados. Essas convergências de práticas e de sentidos nos dão um panorama de inter-relação e partilha entre os diferentes grupos aqui existentes. Não interessa exatamente a origem do rito, interessa que ele foi incorporado na dinâmica social de diferentes grupos como uma regra de etiqueta, de bom convívio.

Nimuendajú (1956, p. 51) também descreveu um jogo realizado com bolas de borracha de dois tamanhos diferentes e tacos de madeira acoplados aos braços dos jogadores. O objetivo do jogo é não deixar as bolas tocarem o chão. Nimuendajú anotou que este jogo também foi descrito entre os Guarani, que vivem ao longo de toda América do Sul concentrando o maior número de falantes na parte sul e noroeste; entre os Tembé, família Tupi-Guarani que vive no Maranhão, Amazonas e Pará; os Xipaya, família Xipaya que vive na Bolívia; e os Warrau ${ }^{4}$, grupo de língua isolada que vive no delta do Orinoco. $\mathrm{O}$ mito que conta a origem deste jogo também é o mesmo entre todos esses grupos de famílias linguísticas diferentes. O mesmo mito em famílias linguísticas diferentes nos aponta a possibilidade de haver tido mais do que trocas materiais entre eles. Talvez uma troca mais profunda que implicou adquirir hábitos e desenvolver gostos, como o gosto pelo jogo de bolas de borracha, que vai muito além de apenas troca. Os jogos praticados não estavam restritos às aldeias, havia campeonatos ou algo semelhante, onde se encontravam os grupos e os times para partilhar comidas, bebidas e competir. Uma grande festa competitiva e esportiva. Pirjo Virtanen esclarece, em seu artigo Constancy in continuity?, incluído no livro Ethnicity in ancient amazonia, organizado por Alf Hornborg e Jonathan Hill, que existem geoglifos no Acre marcando o lugar onde havia competições de jogos de bola de borracha entre vários clãs. Ela salienta que a prática deste jogo se estendia do Brasil central até o Caribe. Por isso, o significado desse jogo não está expresso na morfologia de seu nome. O sentido é historicamente construído e nesse caso, a história desse jogo pode ser uma história de relações entre diversos povos que ultrapassava os limites étnico-territoriais, mas se ancora em um sentido comum que circula por uma região, sem necessariamente haver partilha da morfologia ou empréstimo linguístico.

4. Outras formas de grafar são Warao, Guarauno, Guarao. 
A amplitude dessas dispersões nos dá a dimensão da rede comunicativa da qual faziam parte todos esses povos com suas diferentes línguas. Não significa que eles possuíam uma origem ancestral comum, da qual descenderam os grupos de populações que migraram para povoar o restante do continente. A partilha do rito significa exatamente o rito partilhado. O sentido expresso pelo rito é partilhado por uma rede multilinguística que não se encerra em si mesma. Costumes, regras de etiqueta e gostos nos revelam mais a respeito da interação entre os grupos do que propriamente das origens ancestrais comuns desses grupos. São aproximações paulatinamente constituídas nas e pelas relações de uns com os outros, compreendendo essas relações em termos da interação, dos entendimentos comuns e de práticas integradas, em vez de prever o isolamento ou a segregação entre os grupos. Imaginar um continente permeado por uma história mutuamente significativa é diferente de imaginar um continente de empréstimos linguísticos decorrentes de trocas materiais, incorporações tecnológicas e migrações.

Compreendo que sentidos não são empréstimos linguísticos, mas são fruto de uma ressignificação da condição humana de todo um grupo exposto a um contato mutuamente significativo, e percebo os sentidos partilhados como indicações de uma regionalização da memória discursiva que faz significar aquele sentido em contraste com outras regiões onde aquele sentido não significa ou ao menos não significa da mesma maneira. Em outras palavras, partilha da ideologia. Aqui, entendo ideologia como a manifestação concreta no discurso das formações discursivas materializadas pelas formações sociais expressas pelas relações do homem com o mundo, como elaborado por Michel Pêcheux e Catherine Fuchs (1990, p. 166) em A propósito da análise automática do discurso.

Investigar as bases ideológicas que formam o discurso é uma das tarefas a que me proponho realizar neste artigo, mais especificamente das formações discursivas que dizem respeito às três formas do verbo "comer" em Makuxi (Caribe): yakú (comer papa ou goma), yaní (comer carne de caça ou peixe) e yenápi (comer frutas ou mel); em Kulina (Arawá): hebu (comer peixe ou carne de caça), kadaphi (comer frutas), hau (comer papa), khabaha (comer coisa seca granulada: amendoim, farinha), saka_na (comer carne de gavião ou urubu).

Antes de tudo, não pretendo fazer uma tipologia do verbo "comer". A escolha de tomar duas línguas de famílias linguísticas diferentes nos traz a perspectiva da existência do outro. E o outro serve para perceber as possiveis ligações, identificações ou transferências que traçam as filiações históricas organizadas em memórias e as relações sociais em redes de significantes. Desta forma, a descrição proposta por uma tipologia evidencia o espaço de leitura do discurso do outro como uma lei do espaço social, da memória histórica e do real sócio-histórico. Esse espaço de leitura oferecido pela descrição de um enunciado é o lugar de filiação histórica (palavras, discursos, textos e narrativas) enquanto espaço discursivo logicamente estabilizado. Todo enunciado produzido em um espaço discursivo logicamente estabilizado reflete propriedades estruturais inscritas em uma série de evidências lógicas de uma descrição adequada do universo. Aqui reside o risco de tratar os sentidos do ordinário, do comum, como fatos de natureza psico-biológica inscritos em uma discursividade logicamente estabilizada. Como forma de desfazer este risco, seguindo os preceitos de Pêcheux (2015, p. 43-64), vou aproximar as práticas da análise da linguagem ordinária às práticas de leitura de arranjos discursivo-textuais, entendendo que ambas são gestos de leitura das materialidades discursivas e que, ao tomá-las como gestos de leitura, abro a possibilidade da interpretação dos enunciados através de suas relações com o cotidiano, ou seja, com os rituais ideológicos, os discursos filosóficos, as formas culturais e estéticas, os enunciados políticos. 


\section{Artes culinárias: memória discursiva regional}

A análise do discurso é uma forma de conhecimento que se constrói no contato do histórico com a linguística. Pois é neste ponto onde a materialidade específica do discurso se constitui: na convergência da tensão entre a descrição e a interpretação dos dados linguísticos, da estrutura e do acontecimento, que tomo o discurso como estrutura e acontecimento que se articula no ponto de encontro de uma atualidade e de uma memória. Sendo o discurso, o uso das formações discursivas materializadas pelas formações sociais expressas pelas relações do homem com o mundo, entendo que o real não se reduz à ordem das "coisas-a-saber", mas que é um saber que não se transmite, não se aprende e não se ensina e, no entanto, existe produzindo efeitos (PÊCHEUX, 2015, p. 43-64). Portanto, "comer" é um acontecimento no ponto de encontro de uma atualidade e uma memória.

Como primeira etapa de análise, é preciso converter a superfície linguística (o dado empírico de um discurso concreto) em objeto discursivo (teórico), analisando a materialidade linguística: quem diz, para quem diz, o que diz, em que circunstâncias etc. Com esse primeiro movimento de análise, trabalha-se para desfazer os efeitos de ilusão que sobrepõem pensamento, palavra e coisa, tratando criticamente a impressão de que "aquilo que é dito só poderia ser dito daquela maneira" (ORLANDI, 2015, p. 63).

Assim, viso compreender como o objeto discursivo simbólico produz sentidos. Observam-se o modo de construção, aspectos sintáticos de predicação, estruturação, modo de circulação e as pistas deixadas pelos gestos de interpretação movidos pelos próprios sujeitos dos discursos estudados (mesmo que documentais) que se tecem na história daquelas línguas. A partir desses vestígios de interpretação deixados pelos sujeitos, que nos revelam o modo como esses sujeitos se constituíram em seus discursos, vasculho a produção dos sentidos em seu processo discursivo. Temos, então, três etapas: da superfície linguística para o objeto discursivo e deste para o processo discursivo. O que este trabalho analítico revela são os efeitos da ideologia na língua e a materialização da ideologia na língua. Para a análise do discurso, os processos de assujeitamento e de gestos de interpretação sobre a língua atestam a historicidade dos sentidos nas línguas. Quando se trata de historicidade, não se entende o "conteúdo" da história refletido no texto, mas da materialidade histórica da linguagem: o texto. 0 texto é, portanto, unidade de análise porque organiza a relação da língua com a história no trabalho significante do sujeito em sua relação com o mundo.

A partir das várias camadas de sentidos reveladas, buscarei mergulhar no processo discursivo e na história de constituição desses sujeitos, usando a análise de discurso como ferramenta analítica própria da linguística e como meio de aproximar-me de outras disciplinas que tratam de temas de pesquisa semelhantes, como a história, a antropologia e a arqueologia, e promover um diálogo profuso e construtivo. A etapa inicial já foi, em certa medida, realizada. Ao recortar o corpus e contrastar o consumo de carne e pesca ao de goma e papa, já há a construção da análise que desfaz o dado pronto e revela o processo discursivo. Assim, viso compreender como o objeto discursivo simbólico produz sentidos, seu modo de circulação e as pistas deixadas pelos gestos de interpretação movidos pelos próprios sujeitos dos discursos estudados (mesmo que documentais) que se tecem na história daquelas línguas. A partir desses vestígios de interpretação deixados pelos sujeitos, que nos revelam o modo como esses sujeitos se constituíram em seus discursos, vasculho a produção dos sentidos em seu processo discursivo. 


\section{O objeto discursivo}

Começo pelo caso da oposição entre as formas do verbo "comer" - comer papa ou goma e comer carne de caça ou peixe. Esses objetos discursivos são de talhe estável, pois possuem o privilégio de serem independentes dos enunciados produzidos a seu respeito, como se alguns objetos discursivos fossem mais reais que outros. A independência do objeto face a qualquer discurso feito a seu respeito significa dizer que existe "um real" que determina pontos de impossível, ou seja, aquilo que não pode ser assim. Essa necessidade de fronteiras coincide com a construção de laços de dependência face às múltiplas coisa-a-saber, a começar com o próprio corpo e a diferença entre alimento e excremento. As técnicas materiais e as técnicas de gestão social dos indivíduos delimitam lógicas e estabelecem objetos, coibindo interpretações aleatórias e promovendo um espaço discursivo logicamente estabilizado que produz um mundo semanticamente normal. Pois todo falante sabe do que se fala já que todo enunciado produzido nesses espaços reflete propriedades estruturais independentes de sua enunciação, visto que estão inseridas em uma descrição adequada do universo.

Então, quando contrasto "comer carne e peixe" e "comer papa ou goma", yakú (comer papa ou goma) yant (comer peixe ou carne de caça) - Macuxi hau (comer papa) hebu (comer peixe ou carne de caça) - Kulina

Inicialmente, retomo o entendimento de Pêcheux sobre as "práticas linguísticas inscritas no funcionamento dos aparelhos ideológicos de uma formação econômica e social dada" (PÊCHEUX, 2009, p. 22) e sua reivindicação a respeito de que as análises linguísticas são efeitos das relações de classe sob a dominação da ideologia burguesa. A partir desta preciosa formulação para o entendimento das relações sociais e linguísticas em um "país ocidental" como o Brasil, busco ressignificá-la para a análise linguística das relações de produção em uma sociedade não-capitalista, em que a luta de classes não protagoniza a história das relações sociais, mas que participa da história social da formação econômica deste país.

É importante salientar que a história econômica das sociedades cujas línguas apresento acima se desenrolou de maneira semelhante. Destaco os sentidos expressos nos verbos expostos como a evidência que permite traçar as relações deste andar conjunto e convido a refletir sobre a história econômica e social desta região em tempos pré-coloniais, fazendo um exercício de dispersão e amplitude territorial alcançado pelas práticas de produção e reprodução social expressos nos sentidos dos verbos yakú (comer papa ou goma); yani (comer peixe ou carne de caça); hau (comer papa) e hebu (comer peixe ou carne de caça).

A oposição entre comer algo de origem animal que provém da caça ou da pesca e comer algo de origem vegetal que provém da coleta ou do manejo agrícola nos oferece o entendimento das relações de produção existentes nas dinâmicas sociais circunscritas a aparelhos ideológicos que coibiam outros sentidos e asseguravam a coesão política e ideológica da reprodução social. Entender a estabilização e a circulação dos sentidos em duas línguas indígenas como fruto de um processo de controle políticoideológico é uma maneira de entender a história indígena anterior à chegada do europeu como um processo impulsionado por forças políticas e sociais de coesão e fragmentação que deixou, como marcas de seus processos, esses sentidos que circulam e se dispersam por um amplo território, como um acervo de acomodações sócio-históricas e linguísticas. No entanto, as forças de coesão que constituem 
esses sentidos não partem de um Estado centralizado, mas de uma presença política suficientemente poderosa para coibir outros sentidos e impor determinadas práticas de produção de excedentes e de reprodução social. Tendo em vista que há outros sentidos operando em regiões circunvizinhas, a disputa pela primazia se fazia politicamente ainda mais sensivel, embora não se concretize como uma homogeneidade fonológica ou morfológica na região onde opera linguisticamente.

Trato a consolidação desses sentidos como parte da história econômica, pois entendo que a mobilização de gente em número suficiente para a transformação da paisagem implica em manifestação de poder político para a mobilização da força de trabalho em prol da produção de excedentes. Portanto, passível de um jogo político de disputa de forças. As modificações na paisagem que trato aqui são as construções de tesos e sambaquis usualmente às margens dos rios, em áreas sazonavelmente alagáveis, sempre relacionados a ambientes com recursos diversificados (PUGLIESE, p. 2, 2018). Este tipo de estrutura inclui a escavação de uma barragem e a acumulação de solo para a criação de aterros contíguos à barragem, como na imagem abaixo.

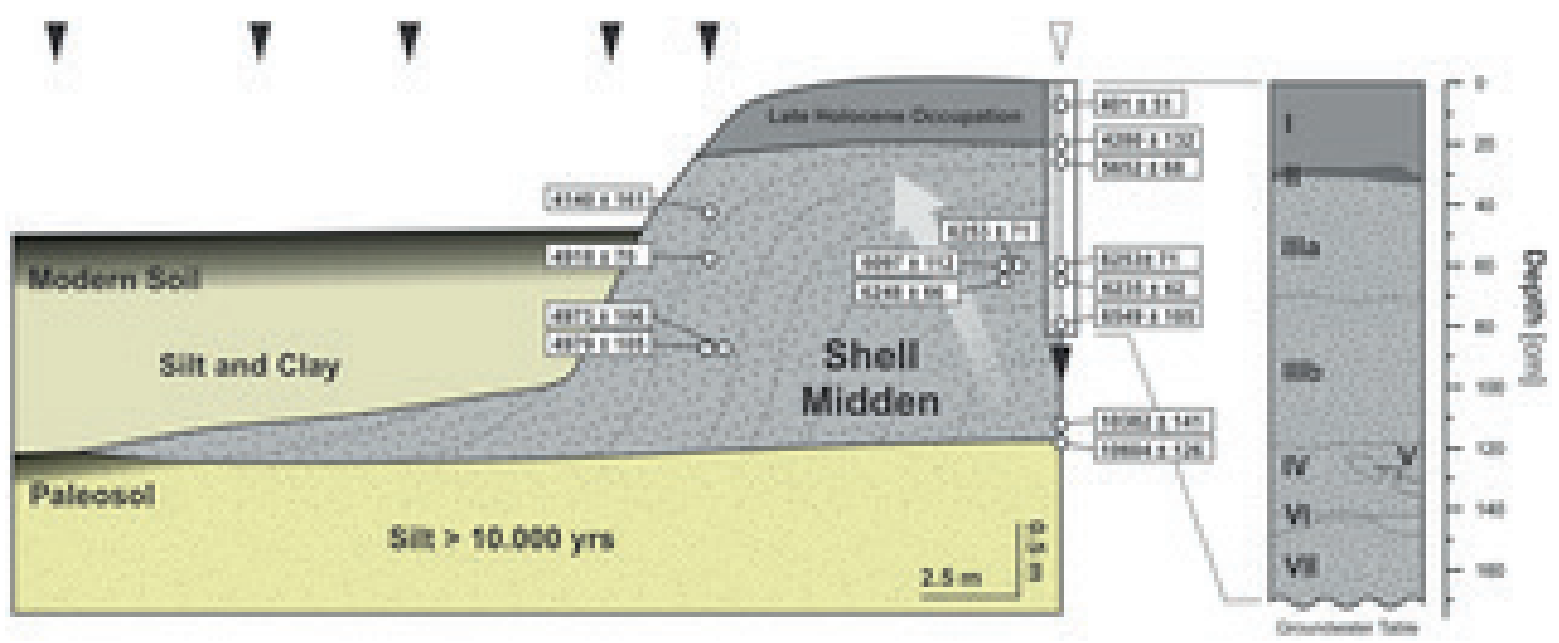

Figura 1: Corte transeccional de um sambaqui (LOMBARDO et al., 2013)

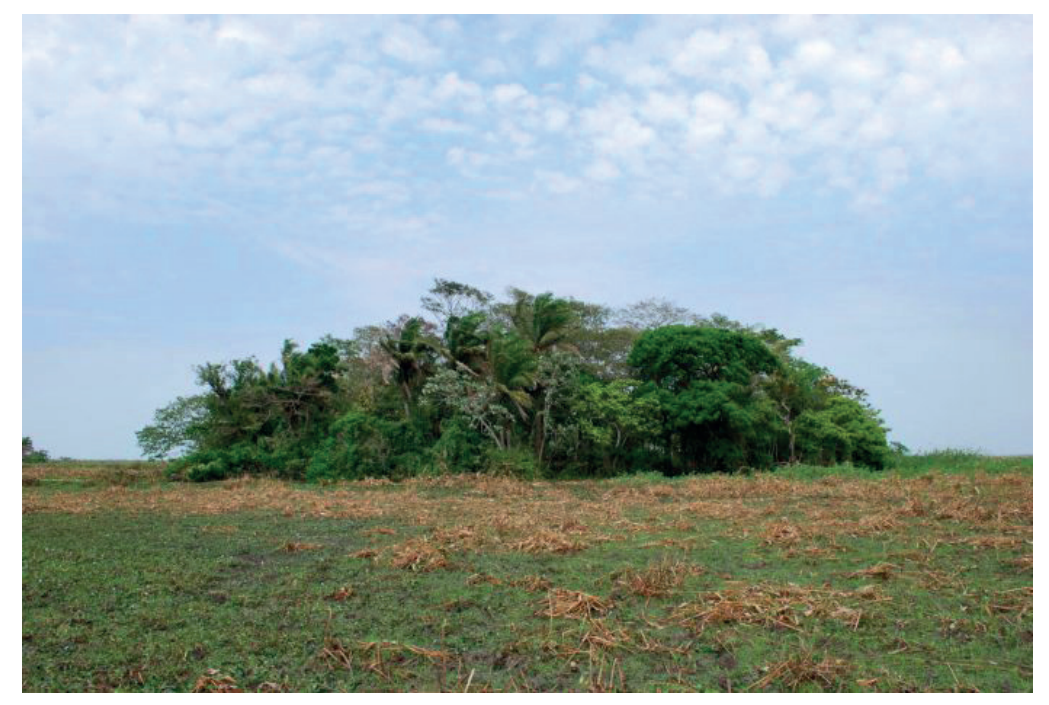

Figura 2: Ilha de floresta (LOMBARDO et al., 2013) 
Estas modificações na paisagem conhecidas como sambaquis e tesos na arqueologia, podem ser encontradas de Llanos de Moxos, na Bolívia até a área costeira da Guiana, argumentado a favor da força política impulsionadora deste modo de produção e dos sentidos materializados nas línguas aqui apresentadas que se encontram em meio a estes dois extremos: Kulina, no Acre e às margens dos rios Juruá e Purus no sudoeste do Estado do Amazonas; e Macuxi, em Roraima, na fronteira com a Guiana.

O deslocamento de solo tornava as barragens mais profundas e propícias para a acumulação de peixes e outros animais como jacarés, e proporcionava o levantamento de pequenas áreas de floresta, onde era possível cultivar e viver, mesmo durante os períodos de cheia sazonal típicos da região. A partir desta construção da paisagem que articula recursos pesqueiros e manejo de espécies vegetais em um conjunto com o regime de chuvas desenvolvo a ideia central deste artigo que revela, em grande medida, a estratégia de produção de comida em ciclos longo e curto derivados do sistema de manejo florestal e das diferentes possibilidades de produção de alimento decorrentes da variação sazonal (MENDES DOS SANTOS, 2016), com estações de mais ou menos chuvas (LÉVI-STRAUSS, 2010; 2011) e toda a mobilidade permitida ou refreada pela sazonalidade das enchentes contrapostas ao período de seca (WHITEHEAD, 2002).

\section{5. yani / hebu (comer peixe ou caça)}

O primeiro caso que trago é yant / hebu "comer peixe ou caça". Em relação à paisagem modificada, yant / hebu significam também a barragem e mais remotamente à própria tarefa de cavar a barragem, historicamente construída pela comunidade com o deslocamento do solo. Às contraposições: "em baixo", na barragem, e "em cima", na ilha; "na água" e "no seco", se somam "espaço de deslocamento" relativo à possibilidade de deslocamento por água, utilizando canoas, durante o período de chuvas, ou caminhando, durante o período de seca, em oposição ao "espaço de permanência", no topo da ilha, onde se vivia, se comia e onde eram sepultados os mortos. As tarefas de pescar e caçar, ambas desempenhadas no "espaço de deslocamento", também significam yaní / hebu em sua relação de oposição complementar ao "espaço de permanência", e são predominantemente masculinas. Simbolicamente, o côncavo e o convexo, o "dentro" e o "sobre", podem representar o estômago, pois o corpo, construído como instrumento, aponta referências espaciais em um mundo culturalmente significado.

Ao elaborar a origem da água terrestre, Lévi-Strauss (2010, p. 250) citou as três formas de comer como as compreendia: canibalismo; pesca; e plantas cultivadas. A cada uma destas formas está associado um período do ciclo das estações, então à estação de seca está associada a coleta de frutas silvestres e a colheita das roças; à água dos rios está associada a pesca nos rios e lagos; e à estação das chuvas está associado o canibalismo. A estação da seca permite deslocar-se caminhando pelo "espaço de deslocamento", propiciando acesso a recursos florestais além dos existentes na ilha próxima à barragem. O período das chuvas exige uma vida reduzida ao âmbito doméstico parcialmente isolada nas ilhas, oferecendo maior contato entre a parentela e estreitando as relações de afeto. No período das chuvas, a pesca se dá nos rios e nos lagos, durante a seca nos lagos e poços, e no auge da seca, na lama dos poços, onde ainda é possível encontrar-se o muçum, hoje em dia pouco pescado, mas que já foi uma importante reserva de alimento para o período da seca. Assim, temos uma associação entre as três formas de comer propostas por Lévi-Strauss, com os verbos em Kulina e Macuxi:

pesca - yant/hebu

plantas cultivadas (manejo agroflorestal) - yakú / hav e yenápí / kadaphi 
O canibalismo, associado ao período das chuvas em que a vida fica mais restrita à aldeia, pode dizer dos sepultamentos que, em geral, ocorrem nas ilhas.

Esta relação entre as formas de comer, traz implicadas as dinâmicas de reprodução social compiladas por Lévi-Strauss (2010, p. 134) no ciclo de mitos da origem da vida breve. A criação das plantas cultivadas, assim como a origem do fogo culinário e as relações matrimoniais, fazem parte do ciclo dos mitos da origem da vida breve, que explicam o estabelecimento da distinção entre natureza e cultura; o processo civilizatório, e a partir dele, a compreensão da vida breve que os seres humanos têm.

Neste conjunto de camadas de sentido que estou descrevendo, há o da convivialidade, pois no ciclo de produção de comida, produz-se um estoque de comida que vai alimentar aqueles que vão trabalhar na pesca. O trabalho da pesca antecede a festa, e o resultado da pesca serve de alimento durante a festa e o sucesso de uma festa depende da quantidade satisfatória de comida a ser servida. Trabalhar junto, viver junto, fazer festa com outras pessoas implica entrar em contato com os venenos emanados por outras pessoas, venenos que contaminam os corpos e precisam ser eliminados depois. Joanna Overig (2006, p. 44) descreveu o uso de alucinógenos (um outro sentido para o veneno) aplicados pelos xamãs em seus pacientes como estratégia de cura e limpeza de todo o veneno absorvido pelo contato com os outros.

\section{6. yakú/ hau "comer papa ou goma"}

No caso de yakú/ hau "comer papa ou goma", há implicado o largo processo de produção da biomassa, que é transformar diferentes vegetais em massa ou em goma, ralando-os e lavando-os como meio de extrair o amido. Em geral, estas etapas são cumpridas por mulheres, sendo portanto, uma tarefa feminina. As biomassas são obtidas a partir de tubérculos, aqui, destaco apenas um deles: a batata-mairá (Casimirella rupestris); de vagens: como, por exemplo, a faveira (Parkia sp.); além de frutos de palmeiras como o buriti (Mauritia flexuosa L. F.), podendo ser preparadas com um só vegetal ou com uma mistura de vários deles, criando um "tempero" ao gosto regional (MENDES DOSSANTOS, 2016, p. 21).

No contexto do rio Negro, esse subproduto extraído dos vegetais é entendido como wehta que significa "elemento estrutural/vital/essencial". Assim, a goma, produto fino último do processo de exploração, é o wehta dos vegetais; o wehta dos animais é a gordura; o wehta dos minerais é a argila; o wehta do corpo humano é o sêmen; o wehta da roça é a coca; e por aí segue5. Embora não haja exemplos de línguas faladas no rio Negro neste artigo, fica o ensinamento a respeito da compreensão de uma essência vital de vegetais e de animais que pode ser extraída e transformada em um subproduto para consumo alimentar.

Depois de extraída, a biomassa pode ser armazenada em cestos e transportada em viagens de canoa ou a pé, garantindo a mobilidade exigida pelas condições climáticas. Produzir biomassa é uma das formas de conservar alimento durante muito tempo, por exemplo, o chamado "pão de índio", que é uma grande bola de biomassa envolvida em látex e enterrada para ser consumida posteriormente (MENDES DOS SANTOS, 2016, p. 22), costuma ser enterrado em terra firme, sob a sombra de uma árvore frondosa, bastando ser desenterrado e consumido. Esta forma de produção e de transporte

5. Comunicação pessoal de Gilton Mendes dos Santos em 25 de outubro de 2019.

Revista Brasileira de Línguas Indígenas - RBLI ISSN 2595-685X https://periodicos.unifap.br/index.php/linguasindigenas Macapá, v. 3, n. 1, p. 122-134, 2020 
nos oferece mais uma camada de relações de sentido que é a de estoque alimentar, de permanência do alimento à disposição para consumo mesmo depois de encerrado o tempo de frutificação ou de colheita das espécies usadas como alimento.

Embora produzir biomassa e plantar roças sejam tarefas femininas, não há uma relação direta da memória discursiva deste verbo com a roça ou com o cultivo, tendo em vista que vários tubérculos, frutas e raízes das quais se produz a biomassa não são cultivados. Em geral, são coletados, como resultado do manejo das espécies disponíveis para consumo na região. Além disso, na roça são produzidos outros vegetais dos quais se extraem venenos, outra forma de essência vital dos vegetais, que é uma tarefa masculina (SHEPARD JR; DALY, 2019, p. 13). Então, a memória discursiva presente está associada ao trabalho feminino de produção de biomassa, voltada à alimentação, não necessariamente à roça. Essa camada de sentidos revelados pelo contraste, a divisão do trabalho feminino e masculino, traz em si outra camada: as relações matrimoniais e as relações de afinidade entre diferentes grupos (OVERIG, 2006; WHITEHEAD, 2002).

A relação masculino e feminino expressa pela divisão de tarefas evoca as relações matrimoniais, que são exogâmicas nos casos Macuxi e Kulina, e expõem o grupo a todo o tipo problemas: feitiços, envenenamento, fofocas e intrigas. Lembro o mito Macuxi descrito por Lévi-Strauss (2010, p. 253), que conta a história de Estrela. Estrela desce à terra, ensina o cultivo e a fermentação aos humanos e se casa. É violada pelo cunhado e se vinga cuspindo sua saliva venenosa no caldo do caxiri que ela foi obrigada a preparar. Vai embora e deixa toda a aldeia envenenada como vingança. Esta história nos mostra a tensão das relações matrimoniais que também entram no ciclo culinário e da reprodução social e formam mais uma camada de sentidos expressos por yakú/ hau "comer papa ou goma".

\section{Breves considerações finais}

Podemos perceber, ao longo deste artigo, que a materialidade linguística de yakú (comer papa ou goma) e yani (comer carne de caça ou peixe) em Macuxi; e hau (comer papa) e hebu (comer peixe ou carne de caça) em Kulina nos revelou uma dicotomia entre duas formas de produzir comida em um mesmo sistema de produção que articula o feminino e o masculino, o alto e o baixo, o seco e a água.

Há também a presença de uma estratégia discursiva que vincula o mundo a um lugar narrativo que não significa uma estrutura de pensamento projetada sobre o real própria de um, mas a relaciona a outras narrativas compartilhadas com vários grupos etnolinguísticos, gerando uma coesão ideológica demonstrada pelos verbos estudados neste artigo.

Deste modo, entendo que uma estrutura narrativa que dá suporte à ideologia que provoca a coesão de sentidos nestas línguas, não é uma projeção do pensamento sobre o real, mas uma estratégia discursiva para criar relações significativas com o mundo. Assim, revela-se uma profunda relação entre grupos sociais considerados linguisticamente apartados. Esta perspectiva pode nos demonstrar vinculações narrativas entre grupos sociais bastante dispersos, do ponto de vista geográfico, mas que apontam para relações comunicacionais e políticas existentes no continente antes da chegada dos europeus. 


\section{Bibliografia}

CERTEAU, Michel de. A Invenção do cotidiano. Artes de Fazer. 9 ed. Petrópolis: Vozes, 2003.

LÉVI-STRAUSS, Claude. O cru e o cozido. Mitológicas I. 2a. ed. São Paulo: Cosac Naify, [1964] 2010.

LÉVI-STRAUSS, Claude. O homem nu. Mitológicas IV. São Paulo: Cosac Naify, 2011.

LOMBARDO, U.; SZABO, K.; CAPRILES, J.M.; MAY, J-H; AMELUNG, W.; HUTTERER, R.; et al. "Early and Middle Holocene Hunter-Gatherer Occupations in Western Amazonia: The Hidden Shell Middens". PLoS ONE 8(8): e72746, 2013. https://doi.org/10.1371/journal.pone.0072746

MENDES DOS SANTOS, Gilton. "Plantas e parentelas. Notas sobre a história da agricultura no Médio Purus." pp. 19-40. In: APARICIO, Miguel; MENDES DOS SANTOS, Gilton (Orgs.). Redes Arawa. Ensaios de etnologia do Médio Purus. Manaus: EDUA, 2016.

ORLANDI, Eni. Análise de discurso. Princípios e procedimentos. 12 ed. Campinas: Pontes, 1999.

ORLANDI, Eni. As formas do silêncio: no movimento dos sentidos. Campinas: Editora Unicamp, 2007.

OVERIG, Joanna. "O fétido odor da morte e os aromas da vida. Poética dos saberes e processo sensorial entre os Piaroa da Bacia do Orinoco." São Paulo, Revista de Antropologia da USP, v. 49, n. 1, 2006. pp. 19-54

PÊCHEUX, Michel. Semântica e Discurso. Uma crítica à afirmação do óbvio. 4. ed. Unicamp: Campinas, 2009.

PUGLIESE, Francisco Antonio; ZIMPEL NETO, C. A.; NEVES, E. G. "What do Amazonian shellmounds tell us about the long-term indigenous History of South America?" Encyclopedia of Global Archaeology, 2018. doi:10.1007/978-3-319-51726-1_3030-1

SHEPARD JR., Glenn; DALY, Lewis. "Magic darts and messenger molecules. Toward a phytoethnography of indigenous Amazonia." New Jersey, EUA, Anthropology Today, vol. 35, n. 2, April 2019, p. 13-17.

WHITEHEAD, Neil. Dark Shamans. Kanaimà and the poetics of violent death. London: Duke University Press, 2002. 